\title{
Flower bud proteome reveals modulation of sex-biased proteins potentially associated with sex expression and modification in dioecious Coccinia grandis
}

Ravi Suresh Devani ${ }^{1,5}$, Tejas Chirmade ${ }^{2,3}$, Sangram Sinha ${ }^{4}$, Abdelhafid Bendahmane ${ }^{5}$, Bhushan B. Dholakia ${ }^{1,2,6}$, Anjan Kumar Banerjee ${ }^{1 *}$ and Jayeeta Banerjee ${ }^{1 *}$ (D)

\begin{abstract}
Background: Dioecy is an important sexual system wherein, male and female flowers are borne on separate unisexual plants. Knowledge of sex-related differences can enhance our understanding in molecular and developmental processes leading to unisexual flower development. Coccinia grandis is a dioecious species belonging to Cucurbitaceae, a family well-known for diverse sexual forms. Male and female plants have 22A + XY and 22A + XX chromosomes, respectively. Previously, we have reported a gynomonoecious form $(22 \mathrm{~A}+\mathrm{XX})$ of $\mathrm{C}$. grandis bearing morphologically hermaphrodite flowers (GyM-H) and female flowers (GyM-F). Also, we have showed that foliar spray of $\mathrm{AgNO}_{3}$ on female plant induces morphologically hermaphrodite bud development $(\mathrm{Ag}-\mathrm{H})$ despite the absence of $\mathrm{Y}$-chromosome.
\end{abstract}

Results: To identify sex-related differences, total proteomes from male, female, GyM-H and Ag-H flower buds at early and middle stages of development were analysed by label-free proteomics. Protein search against the cucumber protein sequences (Phytozome) as well as in silico translated C. grandis flower bud transcriptome database, resulted in the identification of 2426 and 3385 proteins (FDR $\leq 1 \%$ ), respectively. The latter database was chosen for further analysis as it led to the detection of higher number of proteins. Identified proteins were annotated using BLAST2GO pipeline. SWATH-MS-based comparative abundance analysis between Female_Early_vs_ Male_Early, Ag_Early_vs_Female_Early, GyM-H_Middle_vs_Male_Middle and Ag_Middle_vs_Male_Middle led to the identification of 650, 1108, 905 and 805 differentially expressed proteins, respectively, at fold change $\geq 1.5$ and $P \leq 0.05$. Ethylene biosynthesis-related candidates as highlighted in protein interaction network were upregulated in female buds compared to male buds. $\mathrm{AgNO}_{3}$ treatment on female plant induced proteins related to pollen development in Ag-H buds. Additionally, a few proteins governing pollen germination and tube growth were highly enriched in male buds compared to Ag-H and GyM-H buds.

Conclusion: Overall, current proteomic analysis provides insights in the identification of key proteins governing dioecy and unisexual flower development in cucurbitaceae, the second largest horticultural family in terms of economic importance. Also, our results suggest that the ethylene-mediated stamen inhibition might be conserved in dioecious C. grandis similar to its monoecious cucurbit relatives. Further, male-biased proteins associated with pollen germination and tube growth identified here can help in understanding pollen fertility.

Keywords: Coccinia grandis, Dioecy, Sex modification, Stamen arrest, Pollen fertility, Proteomics

\footnotetext{
* Correspondence: akb@iiserpune.ac.in; jayeetab@iiserpune.ac.in

'Biology Division, Indian Institute of Science Education and Research (IISER),

Pune 411008, India

Full list of author information is available at the end of the article
}

(c) The Author(s). 2019 Open Access This article is distributed under the terms of the Creative Commons Attribution 4.0 International License (http://creativecommons.org/licenses/by/4.0/), which permits unrestricted use, distribution, and reproduction in any medium, provided you give appropriate credit to the original author(s) and the source, provide a link to the Creative Commons license, and indicate if changes were made. The Creative Commons Public Domain Dedication waiver (http://creativecommons.org/publicdomain/zero/1.0/) applies to the data made available in this article, unless otherwise stated. 


\section{Background}

Flowering plants show three major sexual systems viz. hermaphroditism, monoecy and dioecy. Around 90\% of the angiosperm species are hermaphroditic bearing perfect flowers having both male as well as female reproductive sex organs [1]. Monoecy exists at a frequency of $\sim 5 \%$ in angiosperms, wherein unisexual male and female flowers are produced on the same individual plant. Remaining $\sim 5 \%$ angiosperm species are dioecious, having separate unisexual plants bearing either only male or female flowers [2-4]. Dioecious species show patchy phylogenetic distribution and are reported in around three-fourth of the angiosperm families. This indicates that the evolution of dioecy has occurred multiple times in different families independently and hence, the molecular mechanisms of sex determination might vary between distant dioecious species and is a matter of great research interest [5-7]. Out of $\sim 14,600$ known dioecious species in 200 families, plant sex chromosomes have been reported in just around 40 species till date [8]. The mechanism of sex determination in plants can be complex and it may also involve environmental factors apart from genetic factors [9].

Coccinia grandis (L.) Voigt, is a dioecious member of Cucurbitaceae, a family known for its diverse sexual systems [10]. In general, C. grandis is not widely used as a model system to understand sex expression and modification. Commonly known as ivy gourd, C. grandis is also used as a vegetable. Male and female unisexual flowers are borne on separate plants. Similar to Silene latifolia (Caryophyllaceae), the presence of large Y-chromosome in male plant determines the sex [11-13]. The chromosome constitution of male and female $C$. grandis plants found to be $22 \mathrm{~A}+\mathrm{XY}$ and $22 \mathrm{~A}+\mathrm{XX}$, respectively [14-16]. The male flower is characterized by the presence of three convoluted (bithecous) stamens and it has no carpel, whereas the female flower possess three rudimentary stamens that surround the three fused carpels having an inferior ovary $[17,18]$.

Two possible explanations can be put forward with respect to unisexual flower development. (1) Primordia for both male and female sex organs are initiated during the early stages of flower development and one of them gets aborted during the later stages (eg: S. latifolia). (2) The flower buds are unisexual right from the inception with the primordia initiation for only one of the two sex organs (eg: Thalictrum dioicum) [19, 20]. In some species, inappropriate sex organs are retained in the rudimentary form instead of getting aborted (eg: Rumex acetosa) [21]. Previously, we have demonstrated that application of $\mathrm{AgNO}_{3}$ on female C. grandis plant modifies the sex expression by inducing stamen development leading to formation of hermaphrodite flowers (such flowers will be referred to as $\mathrm{Ag}-\mathrm{H}$ hereafter) [18]. $\mathrm{Ag}^{+}$ ion is a known inhibitor of ethylene response [22]. Binding of $\mathrm{Ag}^{+}$ion to the ethylene receptor locks the conformation such that it remains continuously active and represses the ethylene responses [23]. Silver compounds $\left(\mathrm{AgNO}_{3}\right.$ and $\left.\mathrm{Ag}_{2} \mathrm{~S}_{2} \mathrm{O}_{3}\right)$ have masculinizing effect on monoecious plants (Cucumis sativus) as well as female plants of dioecious species (S. latifolia and Cannabis sativa) [24-26]. However, the molecular mechanism of $\mathrm{AgNO}_{3}$-mediated induction of stamen development remains unknown till date [26] .

At present, our knowledge about the sex determination mechanisms in plants is fairly limited. Major limitation for studying mechanisms of sex determination in plants is that majority of the dioecious plants are nonmodel organisms without the availability of genome sequence. Hence, the rate at which sex-linked genes are identified from dioecious plant species is very low [27]. However, the advent of NGS (next-generation sequencing) technologies has enabled the high-throughput identification of sex-biased genes from dioecious plant species in recent times [27]. Also, advanced proteomic approaches may lead to the identification of novel sexlinked proteins that can eventually expand our understanding in evolutionary, developmental and molecular mechanism(s) associated with sex determination and modification.

Muyle, et al. [27] took an RNA-Seq approach to identify sex-biased gene expression in S. latifolia and demonstrated the dosage compensation in plants for the first time. Similarly, other transcriptome studies in this plant have helped in understanding the Y chromosome degeneration and identification of new sex-linked genes [28, 29]. Another study in persimmon (Diospyros lotus) showed that OGI (Oppressor of MeGI), a Y-chromosome-encoded small RNA governs pollen fertility by targeting a homeodomain transcription factor $M e G I$ in a dose-dependent manner [30]. Comparative de novo transcriptomics approach taken in Asparagus resulted in identification of genes involved in pollen microspore and tapetum development that were expressed specifically in male flowers [31]. Similar transcriptomics studies have also been carried out in papaya and cucumber that has led to better understanding of sex determination [32-34]. It can be noted that recently, we have carried out a de novo transcriptome profiling from male, female, GyM-H and Ag-H flower buds of $C$. grandis and identified many sex-biased genes that can provide crucial insights in to stamen arrest, pollen fertility and sex modification mechanism [35].

By using transcriptomics over genomics, it is possible to capture differential gene regulations that may arise due to changes in environmental cues/signals or based on the sex of the plant as in case of dioecious species. However, transcriptomics has a disadvantage that the mRNA abundance may not always accurately reflect 
protein levels, which are the end-products in the realization of hereditary information carrying out various structural and functional duties [36, 37]. Moreover, only proteomics can capture the post-translational modifications, which are very well-known to control protein functions. However, proteomics study generally depends on the availability of genomic/transcriptomic data, which is limited for most of the dioecious species. Hence, there are only few studies, which have employed proteomics approach in order to understand sex determination and differentiation in dioecious plants [38]. One such study carried out in Asparagus identified differentially accumulated proteins in the form of spots on 2-D gels from flowers of male and female plants [39]. Another study in Pistacia vera purified a $27 \mathrm{kDa}$ glycoprotein specific to female inflorescence [40]. Proteomic approaches has also been attempted to identify sex-linked proteins in Ginkgo biloba. A $28 \mathrm{kDa}$ protein specific to male and $36 \mathrm{kDa}$ as well as $92 \mathrm{kDa}$ proteins specific to female inflorescences have been identified [38]. Recently, Manzano, et al. [41] showed that overexpression of aerolysin-like protein from the dioecious plant $R$. acetosa induces male sterility in transgenic tobacco.

In order to decipher differences in protein abundances among flower buds of male, female, gynomonoecious and chemically masculinized female plants of C. grandis, total proteome profiling was carried out at early and middle stages of flower development. Proteins were identified using IDA (Information dependent acquisition)-derived data using in silico translated in-house $C$. grandis flower bud transcriptome [35] database followed by label-free quantification using SWATH-MS (Sequential Window Acquisition of All Theoretical Mass Spectra) analysis. Differential protein abundance among various sex forms of $C$. grandis was studied to identify players potentially involved in sex expression and modification. Our study has identified key proteins potentially involved in the processes of stamen arrest, $\mathrm{AgNO}_{3}$-mediated sex modification and pollen fertility in dioecious C. grandis.

\section{Results}

\section{Flower bud proteome of C. grandis}

The tryptic-digested protein samples were analysed by tandem LC-MS in IDA model, and the acquired data was processed by Paragon TM as per experimental scheme shown in Fig. 1. A total of 1193777 spectra (68.8\% of total spectra) corresponding to 66842 distinct peptides representing total 3387 proteins (Additional file 1: Data S1) were identified from different categories of $C$. grandis flower buds with FDR $\leq 1 \%$ (Unused ProtScore Cutoff $>2.0$ ) using in silico translated in-house $C$. grandis flower bud transcriptome (Table 1). Simultaneously, protein identification using Cucumis sativus protein sequences as database led to the identification of 2426 proteins, out of which 434 were new proteins that were not detected using the in silico translated in-house C. grandis flower bud transcriptome (Additional file 1: Data S1). This has further improved the number of proteins identified from the $C$. grandis flower buds in the present study. However, all the following analyses were carried out using C. grandis transcriptome as the database, since it led to the detection of a higher number of proteins.

\section{Annotation of identified proteins}

Proteins identified using ProteinPilot software were searched against viridiplantae subset of $\mathrm{nr}$ (non-redundant proteins) database using BLASTp with an e-value threshold of 1e-3 (Fig. 2a). Total 3377 proteins fetched at least one BLAST hit. More than $95 \%$ of the proteins gave top BLAST hit against C. melo (melon) or C. sativus (cucumber). BLAST2GO was used to annotate and classify the identified proteins into three major gene ontology categories (molecular function, cellular component and biological process) (Additional file 2: Data S2). For biological process, majority of the proteins were involved in metabolic process (1956 proteins) and cellular process (1821 proteins) (Fig. 2b). Interestingly, we could detect 71 proteins annotated with reproduction (GO: 0000003) term (Fig. 2b). Binding (1769 proteins) and catalytic activity (1642 proteins) were two major categories for molecular function (Fig. 2b). Also, 41 proteins with transcription regulator activity were detected (Fig. 2b). Among cellular component, 1243 proteins associated with organelle, while 797 were related with membrane (Fig. 2b) function. The most common enzymes were hydrolases, transferases and oxidoreductases in the identified proteome based on enzyme code distribution analysis (Additional file 3: Figure S1).

\section{Differentially expressed proteins involved in the flower development}

In order to understand how the expression of proteins was regulated during the development of male flower in contrast to female flower, quantitative proteomics was performed using label-free SWATH-MS to identify the DEPs (differentially expressed proteins). Based on the identified proteins from all samples, SWATH-MS analysis led to the detection of total 2262 proteins that were quantified from 144 SWATH data files. PCA-DA (Principal Component Analysis and Discriminant Analysis) showed that replicates belonging to each category of the samples were fairly clustered together. Additionally, upon PCADA analysis, the relationship or differences between different samples as per tissue and/or developmental stages was noticeable. For example, female_early and male_middle flower buds were divergent compared to the rest of flower types (Fig. 3). This clearly reflects the significant variations 


\section{(a)}

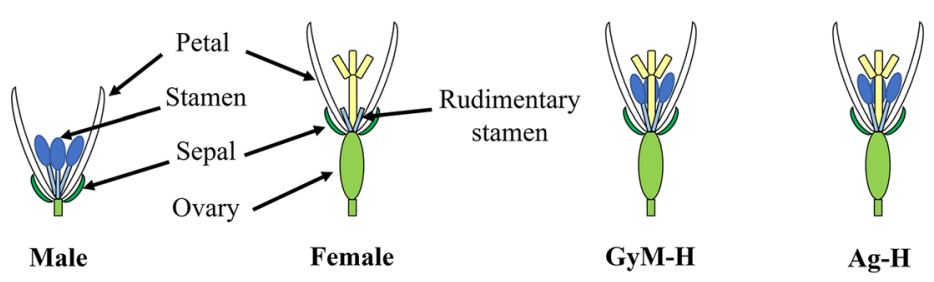

(b)

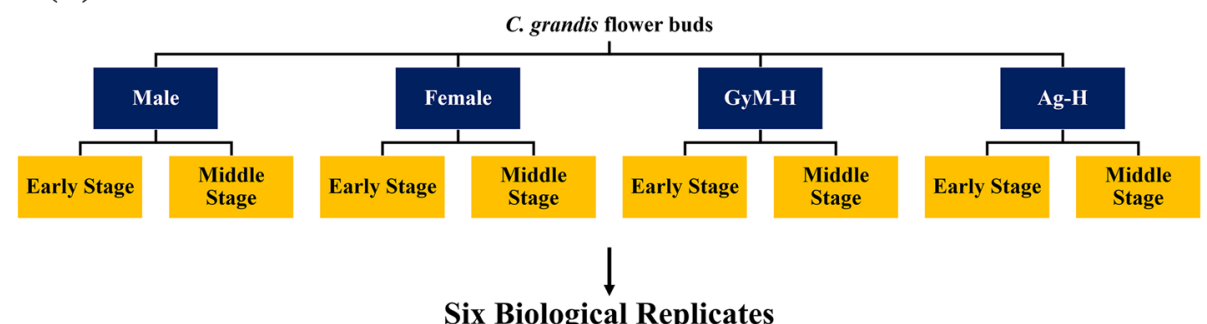

Six Biological Replicates

Protein Extraction and tryptic digestion

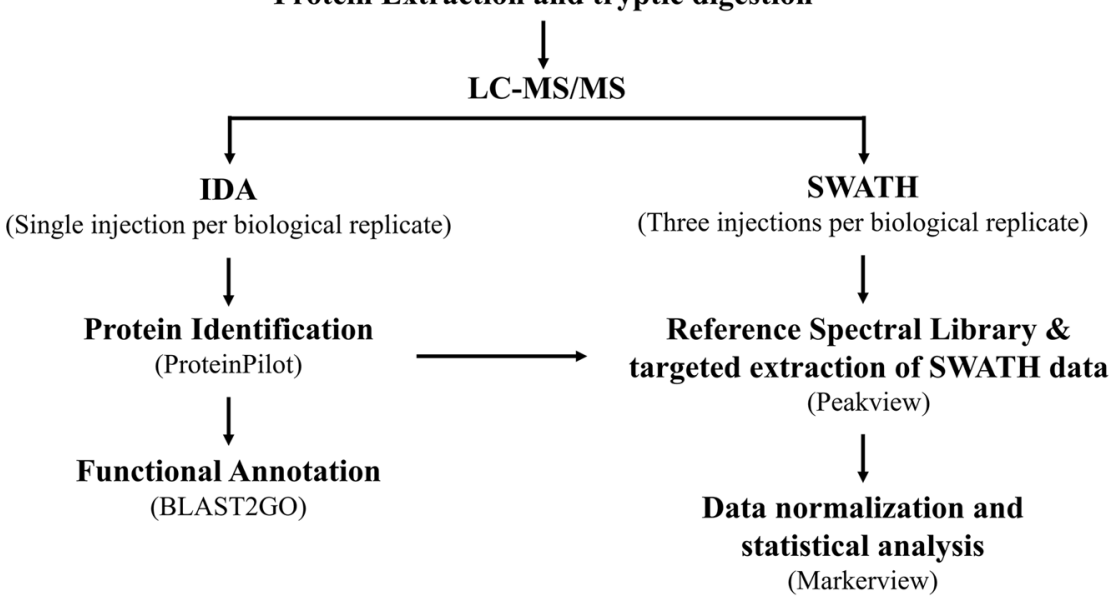

Fig. 1 Scheme for Coccinia grandis flower bud proteomics. a Schematic representation of C. grandis flower types used in current study. b Experimental procedure for flower bud label-free proteomics

in identified proteins as well as their expression levels among different tissues and their developmental stages (Additional file 4: Figure S2). All pairwise comparisons were then made to identify DEPs at fold change $\geq 1.5$ and $P \leq 0.05$. Pairwise comparisons between the proteome profiles of different flower buds at early and middle stages of development are summarized in Table 2. Female_early vs. male_early comparison was made in order to identify key players regulating stamen arrest during female bud development. Interestingly, proteins involved in ethylene biosynthesis such as UBA2A (UBP1-associated protein 2A) (1.61-fold), UBA2C (UBP1-associated protein 2C) (2.1fold) and EFE (Ethylene-forming enzyme) (1.64-fold) were upregulated in early-staged female buds compared to male buds (Fig. 4a \& b). Also, ERS (ethylene response sensor) (4.83-fold Middle) was enriched in middle-staged female

Table 1 Summary of protein identification with AB SCIEX Triple TOF 5600 platform using Paragon Algorithm with ProteinPilot v5.0.1

\begin{tabular}{llllll}
\hline Unused (Conf) Cutoff & Proteins Detected & Proteins Before Grouping & Distinct Peptides & Spectra Identified & \% Total Spectra \\
\hline$>2.0$ (99) & 3387 & 14816 & 66842 & 1193777 & 68.8 \\
$>1.3(95)$ & 3855 & 17469 & 68548 & 1205044 & 69.5 \\
$>0.47$ (66) & 4649 & 21946 & 71945 & 1217799 & 70.2 \\
Cutoff Applied: $>0.05(10 \%)$ & 8979 & 59421 & 87507 & 1256111 & 72.4 \\
\hline
\end{tabular}




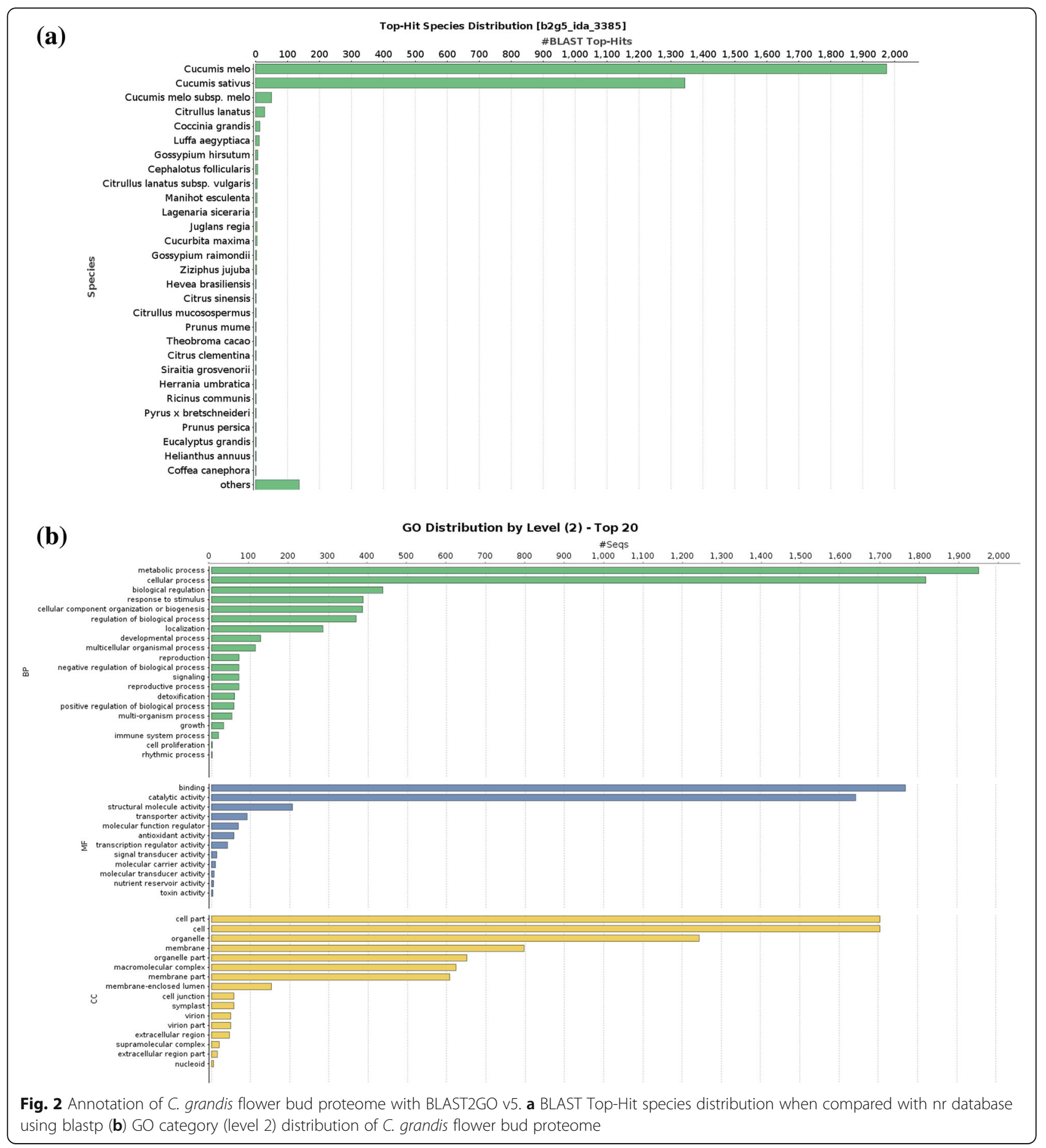

buds compared to male buds (Fig. 4b) (Additional file 5: Data S3). We observed that the expression of AMS (ABORTED MICROSPORES) (0.46-fold) was downregulated in middle-staged female buds compared to male buds (Fig. 5a, b) (Additional file 5: Data S3). Similarly, to identify the effect of $\mathrm{AgNO}_{3}$ treatment on female plant that leads to stamen development, we compared protein profiles of Ag-H_early vs. female_early buds. This comparison resulted in the identification of many male function related proteins that were upregulated upon $\mathrm{AgNO}_{3}$ treatment during early stage such as UGP2 (UTP-glucose-1-phosphate uridylyltransferase 2) (2.41-fold), EDA9 (EMBRYO SAC DEVELOPMENT ARREST 9) (2.05-fold), TKPR1 (Tetraketide alpha-pyrone reductase 1) (2.72-fold), $\mathrm{C} 4 \mathrm{H}$ (Cinnamic acid 4-hydroxylase) (3.53-fold), TPLATE (1.56fold), CDC2 (Cell division control protein 2 homolog A) 


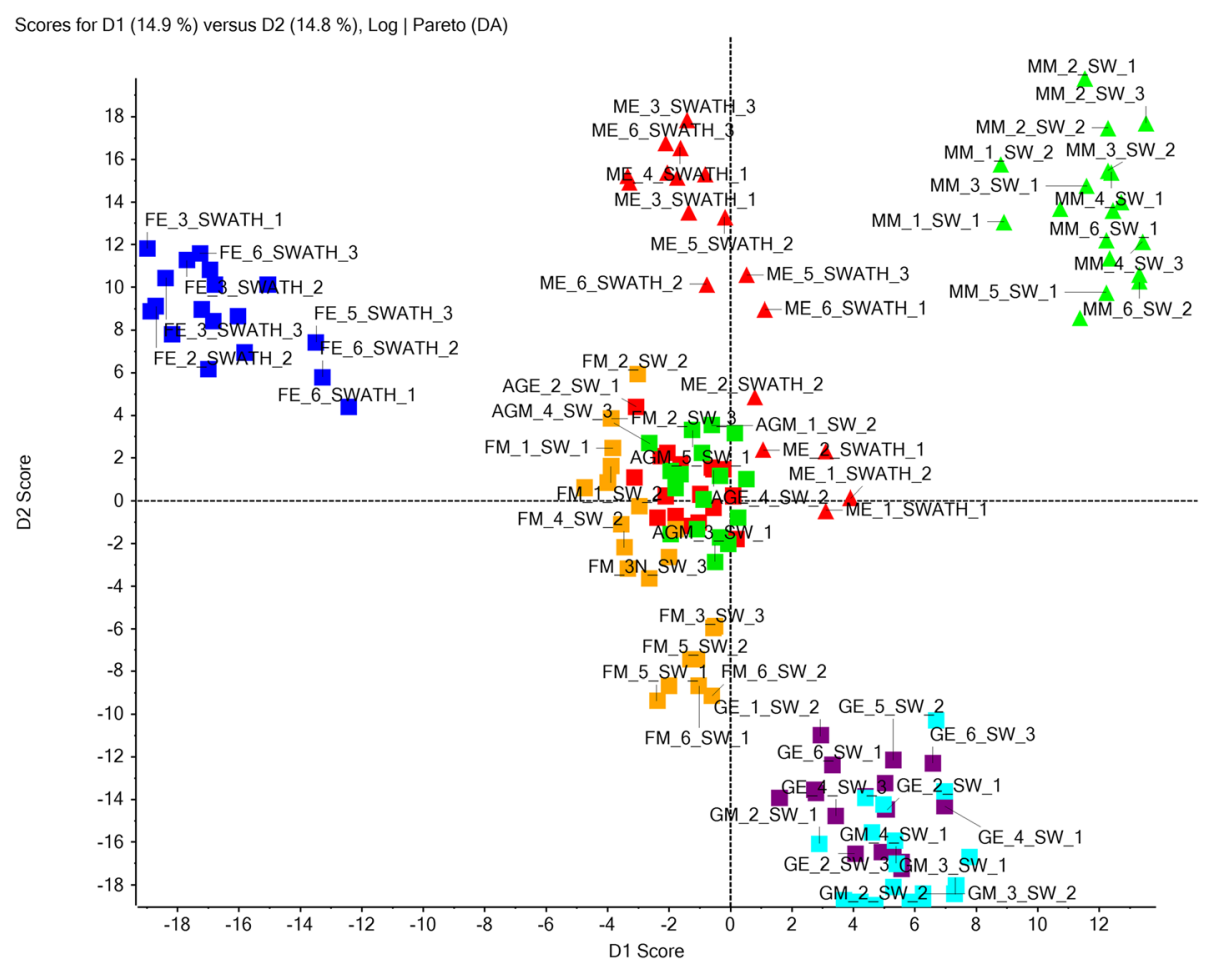

Fig. 3 PCA-DA analysis showing relationship between all the C. grandis flower bud samples as well as replicates in the study. AGE (Red square), Early-staged Ag-H; FE (Blue square), Early-staged Female; GE (Purple square), Early-staged GyM-H; GM (Turquoise square), Middle-staged GyM-H; ME (Red triangle), Early-staged Male; MM (Green triangle), Middle-staged Male; AGM (Green square), Middle-staged Ag-H; FM (Orange square), Middle-staged Female

(3.52), ANN5 (Annexin D5) (1.88-fold), RAB1C (Rasrelated protein $\mathrm{RABD} 2 \mathrm{c})$ (3.13-fold), OASA1 (O-acetylserine sulfhydrylase 1) (3.56-fold), AtkdsA1 (Putative aldolase-type TIM barrel family protein) (4.05-fold), TCTP (Translationally-controlled tumor protein) (2.52fold) and ACAT2 (Acetoacetyl-CoA thiolase 2) (2.71-fold) (Fig. 5b) (Additional file 5: Data S3). Also, many other male function-proteins like USP (UDP-sugar pyrophosphorylase) (1.69-fold), RPN10 (Regulatory particle nonATPase 10) (1.39-fold) and LAP5 (LESS ADHESIVE POLLEN 5) (1.69-fold) were enriched in middle-staged Ag-H buds compared to female buds (Fig. 5b) (Additional file 5: Data S3). The other two comparisons (GyM-H_middle vs. male_middle and Ag-H_middle vs. male_middle)

Table 2 Summary of differentially expressed proteins (DEPs) in pairwise comparisons between male, female, GyM-H and Ag-H flower buds at early and middle stages of development

\begin{tabular}{lll}
\hline Pairwise comparisons & Purpose & Number of DEPs \\
\hline Ag-H Early vs. Female Early & To identify the effect of $\mathrm{AgNO}_{3}$ treatment on female plants that leads to stamen development & 1108 \\
Ag-H Early vs. GyM-H Early & To identify common DEPs involved in stamen arrest compared to female buds & 617 \\
Ag-H Early vs. Male Early & Potential targets that may be involved in pollen development & 872 \\
Ag-H Middle vs. Female Middle & To identify DEPs involved in $\mathrm{Ag}^{+}$-mediated stamen growth & 381 \\
Ag-H Middle vs. GyM-H Middle & To identify common DEPs involved in stamen arrest compared to female buds & 711 \\
Ag-H Middle vs. Male Middle & Potential targets that may be involved in pollen germination and pollen tube growth & 805 \\
Female Early vs. GyM-H Early & To identify DEPs involved in stamen arrest & 1120 \\
Female Early vs. Male Early & To identify proteins regulating stamen arrest during female bud development & 650 \\
Female Middle vs. GyM-H Middle & To identify DEPs involved in stamen arrest during female bud development & 653 \\
Female Middle vs. Male Middle & To identify DEPs involved in stamen arrest and pollen development & 812 \\
GyM-H Early vs. Male Early & Potential targets that may be involved in pollen development & 887 \\
GyM-H Middle vs. Male Middle & Potential targets that may be involved in pollen germination and pollen tube growth & 905
\end{tabular}




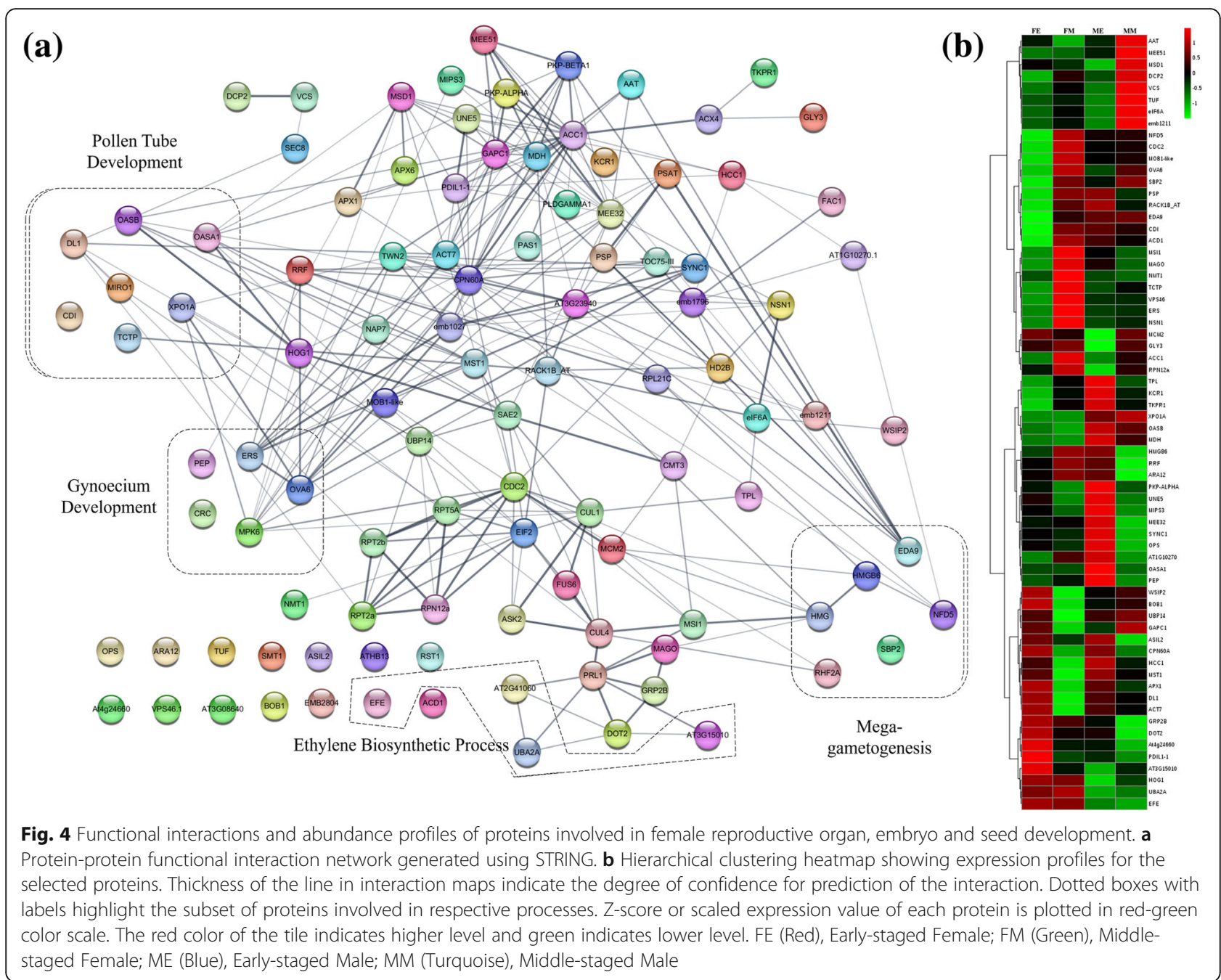

led to the identification of potential targets that may be involved in pollen germination and pollen tube growth. Interestingly, AMS (ABORTED MICROSPORES) (0.24 fold in GyM-H, 0.14 fold in Ag-H), UNE5 (UNFERTILIZED EMBRYO SAC 5) (0.47 fold in Ag-H), iPGAM2 (0.49 fold in GyM-H, 0.46 fold in Ag-H), ACOS5 (Acyl-CoA Synthetase) (0.1 fold in GyM-H, 0.03 fold in Ag-H) and QRT3 (QUARTET 3) (0.14 fold in GyM-H, 0.11 fold in Ag-H) were highly expressed in middle-staged male buds compared to GyM-H and Ag-H buds (Fig. 5b) (Additional file 5: Data S3). Similarly, FUM1 (Fumarate hydratase 1) (0.68 fold in GyM-H, 0.65 fold in $\mathrm{Ag}-\mathrm{H}$ ) was enriched in early-staged male buds compared to GyM$\mathrm{H}$ and $\mathrm{Ag}-\mathrm{H}$ buds (Fig. 5b) (Additional file 5: Data S3). Further, overlap of DEPs among all the pairwise comparisons were analysed for early and middle stages of development (Additional file 6: Figure S3). Interestingly, 66 proteins were unique to the Ag-H_early vs. female early comparison (Additional file 7: Data S4). These proteins could be of particular interest for understanding all the changes induced by $\mathrm{AgNO}_{3}$ leading to sex modification in female plants. Similarly, analysis for middle-staged buds revealed 47 and 73 DEPs that were unique to $\mathrm{Ag}-\mathrm{H}_{-}$ middle vs. male_middle and GyM-H_middle vs. male_ middle comparisons, respectively. These proteins could serve as potential candidates for future studies to understand the pollen fertility in male buds of dioecious cucurbits (Additional file 8: Data S5).

\section{Transcript abundance analysis}

Transcript levels of the selected proteins were validated by qRT-PCR analysis using the same tissues. Coccinia homologs of AIM1, EFE, ETHE1, AMS, TKPR1 and PDIA6 showed interesting transcript abundance profiles with respect to flower bud types (Fig. 6). EFE showed two-fold expression in early-staged female buds as compared to male buds. Pollen development related transcripts AMS, TKPR1 and PDIA6 were enriched in male, GyM-H and Ag-H buds compared to female buds. TKPR1 showed more than 100-fold expression in middle-staged 


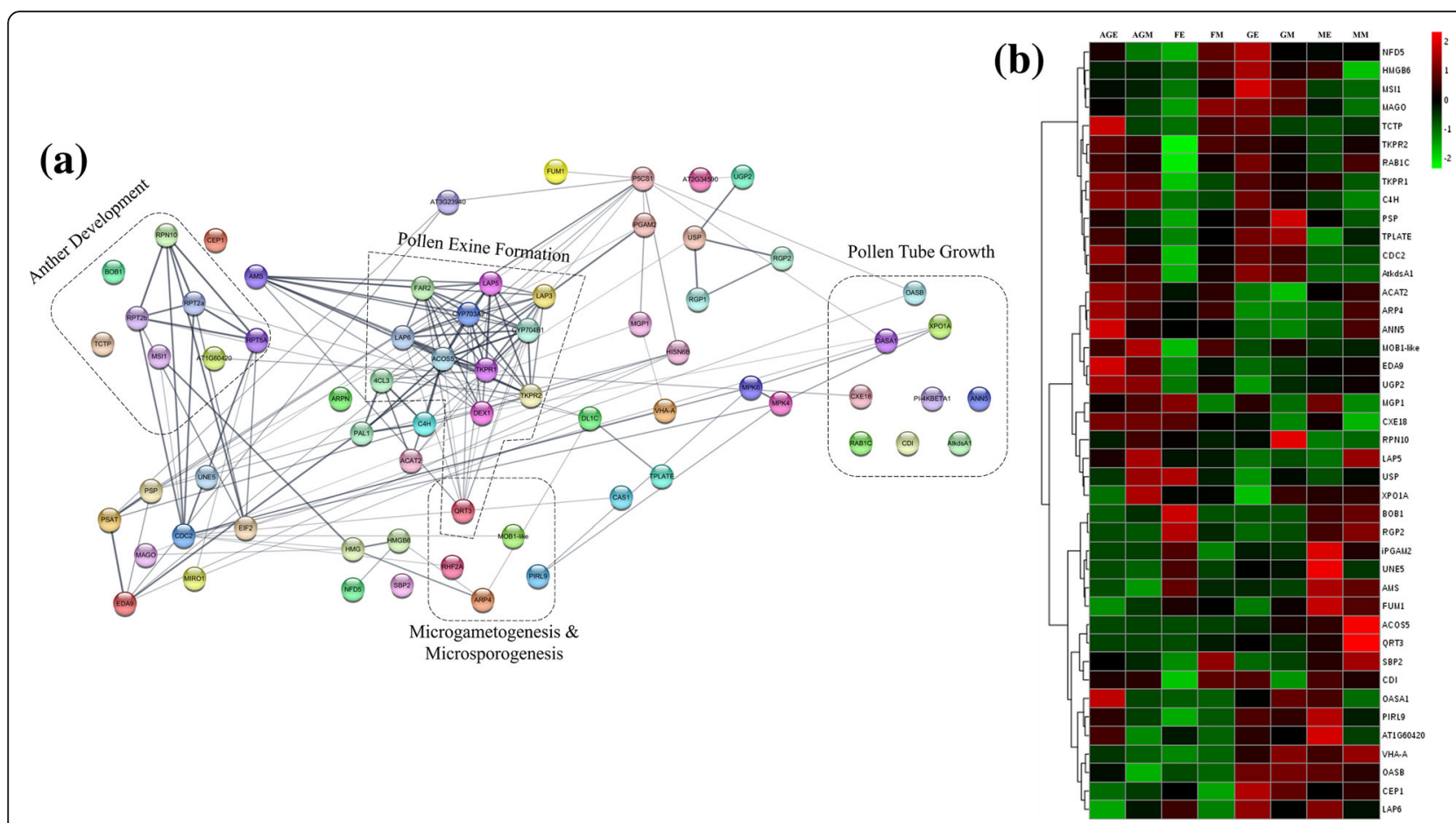

Fig. 5 Functional interactions and abundance profiles of proteins involved in male reproductive organ development. a Protein-protein functional interaction network generated using STRING. $\mathbf{b}$ Hierarchical clustering heatmap showing expression profiles for the selected proteins. Thickness of the line in interaction maps indicate the degree of confidence for prediction of the interaction. Dotted boxes with labels highlight the subset of proteins involved in respective processes. Z-score or scaled expression value of each protein is plotted in red-green color scale. The red color of the tile indicates higher level and green indicates lower level. AGE (Red), Early-staged Ag-H; FE (Blue), Early-staged Female; GE (Pink), Early-staged GyM-H; GM (Yellow), Middle-staged GyM-H; ME (Grey), Early-staged Male; MM (Black), Middle-staged Male; AGM (Green), Middle-staged Ag-H; FM (Turquoise), Middle-staged Female

male buds compared to female buds and was enriched in middle-staged GyM-H and Ag-H buds. AMS homolog exhibited a 100-fold expression in early-staged male buds compared to female buds; > 5-fold levels compared to GyM-H buds and 10-fold increase compared to $\mathrm{Ag}-\mathrm{H}$ buds. However, there were marginal differences between the transcript and the protein levels in some of the genes. For example, PDIA6 protein levels were highest in earlystaged male buds, while $\mathrm{Ag}-\mathrm{H}$ buds showed very low levels. However, in contrast to protein abundance, PDIA6 transcript was most enriched in Ag-H buds. Also, ETHE1 protein levels were found to be the lowest in male bud samples in contrast to the transcript levels.

\section{Protein interaction network reveals presence of potential targets from reproductive organ development}

The proteins identified in relation to reproductive organ, embryo and seed development were further used for protein-protein functional interaction mapping. STRING analysis for 42 male reproductive organ development-related proteins resulted in a functional interaction map indicating anther and pollen development, pollen tube growth as well as microgametogenesis and microsporogenesis related function proteins (Fig. 5a) (Additional file 9:
Data S6). Expression analysis of these proteins indicated that majority were enriched in male, GyM-H and $\mathrm{Ag}-\mathrm{H}$ buds compared to female buds (Fig. 5b). Similarly, another STRING analysis of 66 identified proteins related to female reproductive organ, embryo and seed development led to the identification of protein interaction networks governing gynoecium development, ethylene biosynthesis, megagametogenesis and pollen tube development (Fig. 4a) (Additional file 9: Data S6). Importantly, proteins from gynoecium development and ethylene biosynthesis related clusters were enriched in female buds (Fig. 4b). This might lead to the stamen inhibition in female buds and explain the absence of gynoecium in male buds.

\section{Discussion}

\section{Comparative profiles of proteins involved in female reproductive functions}

Our study is one of the few proteomic reports focused on identification of proteins involved in unisexual flower development. We compared the protein profiles of male and female buds of Coccinia at early as well as middle stages of development and identified proteins related to male and female reproductive organ development. At early stage, female flower buds of $C$. grandis exhibit the 


\section{EFE}

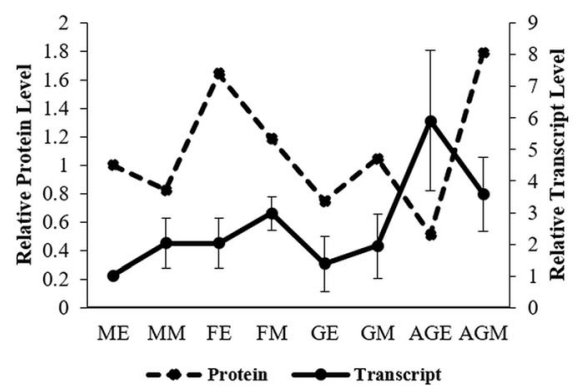

PDIA6

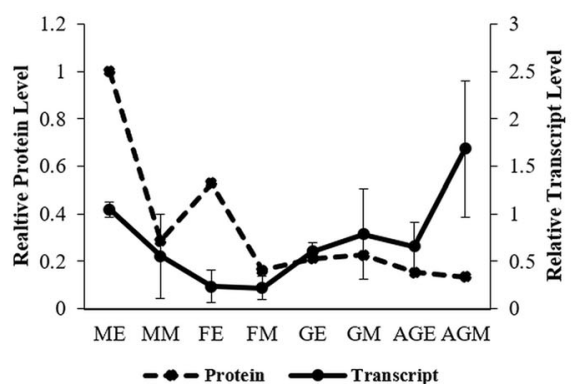

TKPR1

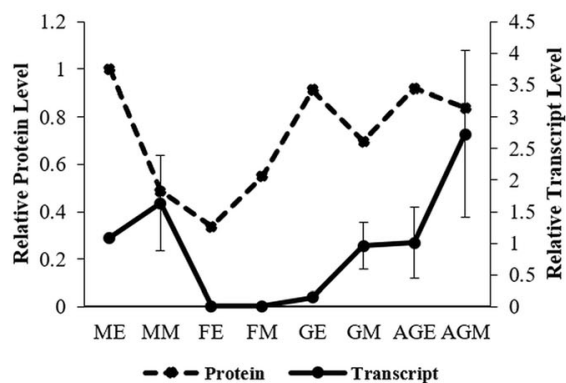

AIM1

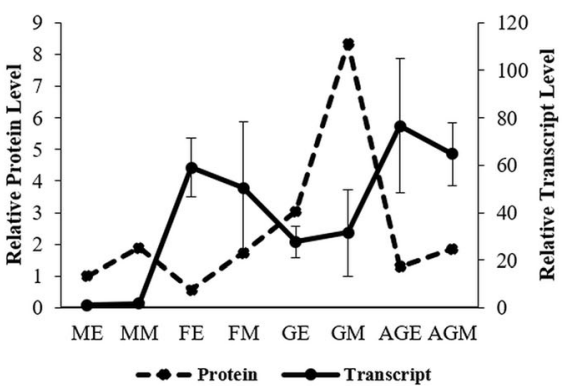

AMS

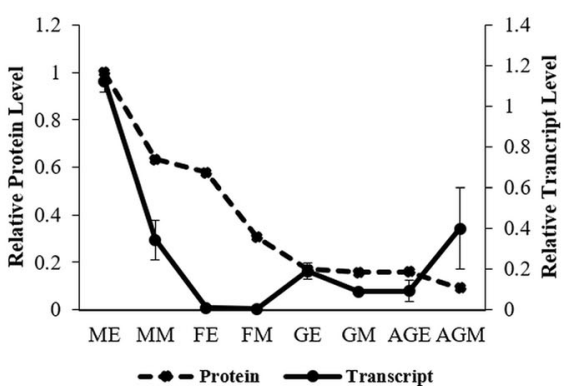

ETHE1

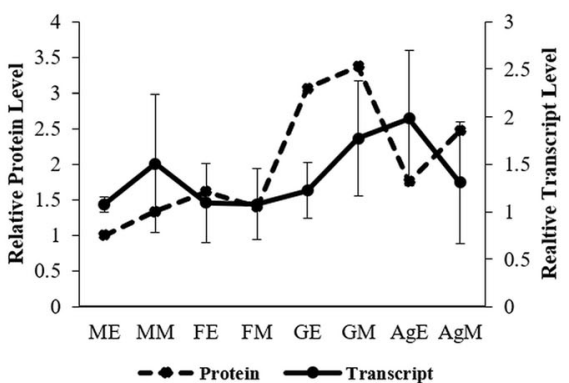

Fig. 6 Transcript abundance analysis for selected DE proteins by qRT-PCR with three biological replicates. The relative abundance of transcripts (based on qRT-PCR) and proteins (based on SWATH analysis) in the sample of early-staged male (ME) were set to 1 for plotting the data. Error bars indicate the standard deviation. AgEA, Early-staged Ag-H A; AgEB, Early-staged Ag-H B; FEA, Early-staged Female A; FEB, Early-staged Female B; GEA, Early-staged GyM-H A; GEB, Earlystaged GyM-H B; GMA, Middle-staged GyM-H A; GMB, Middle-staged GyM-H B; MEA, Early-staged Male A; MEB, Early-staged Male B; MMA, Middle-staged Male A; MMB, Middle-staged Male B; AgMA, Middle-staged Ag-H A, AgMB, Middle-staged Ag-H B; FMA, Middle-staged Female A; FMB, Middle-staged Female B

growth of both stamens and carpels. However, before the flowers reaches to middle stage of development, stamen gets arrested in female buds. The mechanism of stamen arrest has been well studied in monoecious relatives of Coccinia such as melon, cucumber and watermelon. However, we have no clue about the stamen arrest in unisexual flower of Coccinia [42-45]. ACS (ACC synthase), an enzyme involved in ethylene biosynthesis is found to be expressed at very high levels in female buds of melon, cucumber and watermelon compared to the male buds. High levels of ethylene in female bud act as an inhibitor of stamen development [42-46]. However it is not known, if the ACS function is conserved in dioecious cucurbits. Previously, we have shown that GO terms related to ethylene signalling were enriched in female buds of C. grandis [35]. In present study however, we couldn't detect ACS from the flower buds. Instead, we found that the inducers of ACS, namely UBA2A (UBP1-associated protein 2A) and UBA2C (UBP1-associated protein $2 \mathrm{C}$ ) had very high abundance in female $C$. grandis buds compared to male buds (Fig. 4a \& b). In Arabidopsis, Kim, et al. [47] showed that overexpression of UBA2A and UBA2C induces the expression of various ACS genes. EFE (Ethylene-forming enzyme), another enzyme involved in ethylene biosynthesis was also enriched in early as well as middle-staged female buds compared to male samples (Fig. 4a, b). CsACO2 gene, an EFE homolog is known to 
be essential for the carpel development in cucumber [48]. Recently, Tao, et al. [49] reported that Ethylene responsive factor (ERF110) mediates ethylene-regulated transcription of sex determination related orthologous gene ACS11 in melon and cucumber. This evidence further supports the role of ethylene in governing the sex expression in cucurbits. Moreover, we observed that female buds of C. grandis also showed much higher accumulation of ERS (Ethylene response sensor), an ethylene receptor at middle stages of development compared to male buds (Fig. 4a \& b) [50]. This indicates that ethylene levels as well as ethylene responses are higher even in the female buds of dioecious C. grandis similar to the female buds of monoecious cucurbits. This perhaps explains the cause of stamen arrest in C. grandis; however, further functional studies are required to validate this hypothesis. Apart from this, OVA6 (OVULE ABORTION 6) involved in ovule development was enriched in the female buds and the male flowers of C. grandis didn't show any sign of female reproductive organs (Fig. 4a \& b) [51]. Levels of proteins involved in embryo development such MAGO, VPS46 (Vacuolar protein-sorting-associated protein 46), PDIL1-1(Protein disulfide isomerase-like 1-1), GRP2B (Glycine-rich protein 2b), At4g24660 (Zinc-finger homeodomain protein 2) were also increased in female buds compared to male counterparts (Fig. 4a \& b) [52-55]. MAGO, a protein involved in pollen tube guidance was expressed in female buds at middle stage of development indicating the maturation of female buds for supporting fertilization (Fig. 4a \& b) [56].

\section{$\mathrm{AgNO}_{3}$ treatment induces changes in protein profiles affecting sex modification}

In previous study, we have shown that foliar spray of $\mathrm{AgNO}_{3}$ at optimal concentration $(35 \mathrm{mM})$ can induce stamen development in the newly emerging flower buds of female plants resulting in sex modification [18]. The morphologically hermaphrodite flowers $(\mathrm{Ag}-\mathrm{H})$ have full-sized stamens surrounding the carpels. Based on earlier de novo transcriptomics study and the literature available for sex determination mechanism in monoecious relatives of Coccinia (melon, cucumber and watermelon), we hypothesized that $\mathrm{Ag}^{+}$ions bring about the sex modification by inhibiting ethylene signalling [35, 42-45, 48, 57, 58]. CmACS7 acts as an inhibitor of stamen development in melon by playing a role in ethylene biosynthesis [42]. Through transcriptomics study, we had shown that $\mathrm{AgNO}_{3}$ spray resulted in inhibition of ethylene signalling in $C$. grandis [35]. In the present report, we observed that Coccinia homologs of many proteins involved in pollen development such as USP (UDP-sugar pyrophosphorylase), RPN10 (Regulatory particle non-ATPase 10), UGP2 (UTP-glucose1-phosphate uridylyltransferase 2), EDA9 (Embryo sac Development Arrest 9), TKPR1 (Tetraketide alpha-pyrone reductase 1), $\mathrm{C} 4 \mathrm{H}$ (Cinnamic acid 4-hydroxylase), TPLATE, CDC2 (Cell division control protein 2 homolog A), ANN5 (Annexin D5), RAB1C (Ras-related protein RABD2c) were enriched in Ag-H buds compared to female buds [59-69] (Fig. 5a \& b). LAP5 (LESS ADHESIVE POLLEN 5), TKPR1 and TKPR2 (Tetraketide alpha-pyrone reductase 2), which are involved in sporopollenin biosynthesis and pollen exine formation were upregulated upon $\mathrm{AgNO}_{3}$ treatment (Fig. 5a, b) [63, 64, 70, 71]. Also, Coccinia homologs for OASA1 (O-acetylserine sulfhydrylase 1), AtkdsA1 (Putative aldolase-type TIM barrel family protein), TCTP (Translationally-controlled tumor protein), ACAT2 (Acetoacetyl-CoA thiolase 2), ANN5, RAB1C proteins involved in pollen germination and pollen tube growth were enriched in Ag- $\mathrm{H}$ buds compared to female buds (Fig. 5a \& b) [68, 69, 72-74]. Although, these proteins were expressed upon $\mathrm{AgNO}_{3}$ treatment, the pollens of Ag-H buds failed to germinate in vitro as well as did not fertilize the female buds [18]. Interestingly, $\mathrm{Ag}^{+}$ions were able to induce the development of stamens even in absence of Y-chromosome, which would otherwise get arrested in female plants [18]. We speculate that Y-chromosome may be essential for providing pollen fertility as the pollens from $\mathrm{Ag}-\mathrm{H}$ flowers buds were sterile in nature.

\section{Pollen maturation in male, GyM-H and Ag-H buds}

Comparison of protein accumulation profiles from male buds to those of GyM-H and Ag-H buds resulted in the identification of many proteins that were expressed at different levels in these flower types. Coccinia homologs of proteins such as LAP6 (LESS ADHESIVE POLLEN 6), CEP1 (KDEL-tailed cysteine endopeptidase), OASB (O-acetylserine sulfhydrylase B), VHA-A (V-type proton ATPase subunit a3) and PIRL9 (Plant intracellular Rasgroup-related LRR protein 9) were enriched in male and GyM-H buds compared to Ag-H and female buds (Fig. 5a \& b). LAP6 protein known to be involved in pollen exine formation/sporopollenin biosynthesis in Arabidopsis, was found to be enriched in male and GyM-H buds compared to Ag-H and female buds of C. grandis (Fig. 5a \& b) $[70,71]$. In contrast, LAP5, (also involved in pollen exine formation) was seen to be enriched in male and Ag-H buds but not in GyM-H and female buds (Fig. 5a \& b) $[70,71]$. A mutation in Arabidopsis CEP1, a KDEL-tailed cysteine endopeptidase, has been shown to exhibit aborted tapetal PCD and decreased pollen fertility with abnormal pollen exine [75]. On the other hand, VHA-A (V-type proton ATPase catalytic subunit A) protein is strictly required for proper development of male gametophyte [76]. Consistently, VHA-A had a high expression in male and GyM-H buds (Fig. 5a \& b). Plant intracellular ras-group-related LRR protein (PIRL9) has been shown to play an important role in the process of 
microgametogenesis and pollen development [77]. PIRL9 had high expression in male and GyM flower buds (Fig. 5a \& b). OASB (O-acetylserine sulfhydrylase) protein that has been known to be required for pollen tube elongation and fertilization in Arabidopsis showed high expression in male and GyM-H flower buds (Fig. 5v) [74].

Many proteins, however, were enriched specifically in male buds with very low levels in GyM-H, Ag- $\mathrm{H}$ and female buds. AMS (ABORTED MICROSPORES), UNE5 (UNFERTILIZED EMBRYO SAC 5) and IPGAM2 Coccinia homologs were enriched in middle-staged male buds (Fig. 5a \& b). UNE5 is known to be important in the process of pollen tube development [78]. Mutation in transcription factor AMS (ABORTED MICROSPORES) results in defective tapetum development, abnormal microspores and non-viable pollens [79]. Similarly, Coccinia homologs ACOS5 (Acyl-CoA Synthetase) and QRT3 (QUARTET 3) involved in pollen exine formation were also enriched in middle-staged male buds (Fig. 5a \& b) $[64,80,81]$. Another protein FUM1 (Fumarate hydratase 1 ), involved in pollen tube development was enriched in early-staged male buds compared to GyM-H and $\mathrm{Ag}-\mathrm{H}$ buds (Fig. 5a \& b) [78]. All these observations indicate that these proteins probably govern the pollen viability and lack of their expression in GyM-H and $\mathrm{Ag}-\mathrm{H}$ buds leads to the sterile pollens.

\section{Conclusion}

Current study has led to the identification of many proteins expressed in the flower buds of male, female and gynomonoecious forms of Coccinia grandis at early and middle stages of development. Protein search against the in silico translated C. grandis flower bud transcriptome database has resulted in the identification of 3385 proteins. Simultaneously, protein search analysis against cucumber protein sequences (Phytozome) led to 434 new proteins that could not be detected through $C$. grandis flower bud transcriptome. This has further improved the number of proteins identified from the $C$. grandis flower buds in the current study. Also, changes in the proteome profile upon $\mathrm{AgNO}_{3}$-mediated sex modification in female plants were revealed. Through protein interaction network maps, we observed that proteins involved in ethylene biosynthesis such as UBA2A, UBA2C and EFE were upregulated in female buds of $C$. grandis indicating high levels of ethylene similar to the female buds of monoecious cucurbits such as melon, cucumber and watermelon. This could suggest that the role of ethylene in stamen inhibition might be conserved not only in monoecious cucurbits but also in dioecious C. grandis. $\mathrm{AgNO}_{3}$ treatment was able to induce stamen development in female plants of $C$. grandis. However, the pollens from $\mathrm{Ag}-\mathrm{H}$ and $\mathrm{GyM}-\mathrm{H}$ buds were sterile in nature. There could be two possibilities to explain the cause of pollen sterility in $\mathrm{GyM}-\mathrm{H}$ and $\mathrm{Ag}-\mathrm{H}$ flower buds. The flower buds of gynomonoecious and male plants could differ in the timing or level of gene expression leading towards the incomplete development of pollens. Alternatively, genes governing pollen fertility might be Y-linked and absent from $\mathrm{GyM}-\mathrm{H}$ and $\mathrm{Ag}-\mathrm{H}$ forms. As till now, complete genome sequence of Coccinia is not available, it would be difficult to ascertain this. Future investigation is required to unravel the mechanistic link between ethylene mediated stamen inhibition as well as the role of Y-chromosome in pollen fertility. Overall, in light of the limited molecular resources for such non-model dioecious species, our current flower bud proteome datasets will serve as invaluable novel resources for future identification of key molecular players involved in the development of unisexual flowers in cucurbitaceae, the second largest horticultural plant family in terms of economic importance.

\section{Methods \\ Flower bud collection}

Clones of wild-type male, female and gynomonoecious (GyM, herbarium voucher: Tripura University Campus, Karmakar, 433) forms of C. grandis were grown in the experimental plot at IISER Pune, India [18]. Some of the female plants were chemically masculinized by a foliar spray of $35 \mathrm{mM} \mathrm{AgNO} 3$ solution to the basal leaves, leading to the development of morphologically hermaphrodite flowers (Ag-H). Both early and middle-staged flower buds of male, female, gynomonoecious and chemically masculinized female plants of $C$. grandis were harvested as per the prevoius protocol [35]. Six biological replicates for each of the samples were used in this study. Each biological replicate consisted of a pool of 45 flower buds of uniform size, crushed in liquid nitrogen and stored at $-80{ }^{\circ} \mathrm{C}$ until further use. Overall, experimental plan is depicted schematically in Fig. 1. Earlystaged male flower buds chosen for this study showed the development of stamen intitials without any sign of carpel initials, while early-staged female flower buds (stages 3-4) had both carpel as well as stamen initials. We have noticed that stamen growth in female flower gets arrested around stages 4-5 [18]. The early-staged flower buds were chosen such that the stamen inhibition regulation can be studied [35]. However, in both types of hermaphrodite flowers ( $\mathrm{Ag}-\mathrm{H}$ and GyM-H), stamens and carpels develop simultaneously during early as well as middle stages of development. Pollen maturation process was also of interest since only male flowers produced viable pollens. Both types of hermaphrodite flowers (Ag- $\mathrm{H}$ and GyM-H) produced non-viable pollens [18]. Hence, middle-staged flower buds were chosen such that pollen maturation process can be investigated [35]. 


\section{Protein extraction}

Protein extraction was carried out from flower buds of C. grandis as per Isaacson, et al. [82] with some modifications. Flower buds were crushed fine in liquid nitrogen and $50 \mathrm{mg}$ of the powdered samples, weighed in $15 \mathrm{~mL}$ tubes (TARSONS) were used for each biological replicate. Five $\mathrm{mL}$ of chilled $10 \% \mathrm{TCA}$ /Acetone with $2 \% \beta$ mercaptoethanol was added to these tubes, vortexed and incubated for at least $4 \mathrm{~h}$ at $-20^{\circ} \mathrm{C}$. The tubes were further centrifuged at $10000 \mathrm{rpm}$ for 20 mins and the supernatant was carefully discarded. The excess acetone in the pellet was evaporated in the fume-hood. Ten mg of insoluble PVPP (Polyvinylpolypyrrolidone) was added to this pellet followed by addition of $5 \mathrm{~mL}$ of extraction buffer containing $0.7 \mathrm{M}$ sucrose, $0.1 \mathrm{M} \mathrm{KCl}, 0.5 \mathrm{M}$ Tris- $\mathrm{HCl}$, $\mathrm{pH} 7.5,50 \mathrm{mM}$ EDTA, $0.5 \%$ SDS and $\beta$-mercaptoethanol at a final concentration of $2 \%(\mathrm{v} / \mathrm{v})$ and vortexed vigorously for 15 mins. The tubes were centrifuged for 20 mins at $4{ }^{\circ} \mathrm{C}$ and $10000 \mathrm{rpm}$. The supernatant was transferred to a fresh $15 \mathrm{~mL}$ tube to which $5 \mathrm{~mL}$ Tris equilibrated phenol (pH 8.0) was added and vortexed vigorously for 15 mins. Phase separation was carried out by centrifugation at $10000 \mathrm{rpm}$ for $20 \mathrm{mins}$ at $25^{\circ} \mathrm{C}$. The upper phenolic phase was transferred to a fresh tube and washed with the extraction buffer (without SDS). The process was repeated twice and the protein was precipitated using 3-5 volumes of chilled $0.1 \mathrm{M}$ ammonium acetate in methanol containing $2 \% \beta$-mercaptoethanol. Pelleting and washing of the protein was performed as described previously [82]. The dried protein pellet was reconstituted in $0.1 \%$ RapiGest SF (Waters) and quantitated using Bradford method (microtitre plate method, BioRad).

\section{In-solution digestion and peptide purification}

For in-solution digestion of the extracted proteins, $100 \mu \mathrm{g}$ of reconstituted proteins was taken in $1.5 \mathrm{~mL}$ LoBind tubes (Eppendorf) and diluted using 0.1\% RapiGest $\mathrm{SF}$ (prepared in fresh $50 \mathrm{mM}$ ammonium bicarbonate solution) to make a final volume of $100 \mu \mathrm{L}$. This protein solution was heated at $80^{\circ} \mathrm{C}$ for 15 mins on thermomixer at $1250 \mathrm{rpm}$. Five $\mu \mathrm{L}$ of $100 \mathrm{mM}$ DTT (Dithiothreitol, freshly prepared) was added to the preheated protein solution and incubated at $60^{\circ} \mathrm{C}, 1250 \mathrm{rpm}$ for $15 \mathrm{mins}$. The protein solution was cooled to room temperature and $5 \mu \mathrm{L}$ of $200 \mathrm{mM}$ iodoacetamide was added and incubated in dark for 30 mins at room temperature. Three $\mu \mathrm{g}$ of trypsin (Trypsin GOLD, Promega, MS-Grade) was added to the protein for digestion and incubated for $16 \mathrm{~h}$ at $37^{\circ} \mathrm{C}$ and $1250 \mathrm{rpm}$. The reaction was stopped by adding $2 \mu \mathrm{L}$ of formic acid (Sigma, MS-Grade) and incubated at $37^{\circ} \mathrm{C}$ under static condition for 45 mins. The tubes were centrifuged at $15000 \mathrm{rpm}$ for $30 \mathrm{mins}$ at $4{ }^{\circ} \mathrm{C}$ and supernatant was collected in a fresh $1.5 \mathrm{~mL}$ LoBind tube and stored at $-80^{\circ} \mathrm{C}$ until further use. The tryptic peptides were purified using C18 ZipTip (Milipore) by following manufacturer's instructions. The peptide fractions were vacuum dried and reconstituted using 3\% ACN with $0.1 \%$ formic acid to yield a final concentration of $1 \mu \mathrm{g} / \mu \mathrm{L}$.

\section{MS data acquisition for IDA and SWATH}

The reconstituted peptides were further diluted to yield concentrations of $3 \mu \mathrm{g} / 5 \mu \mathrm{L}$ for IDA acquisitions and $1 \mu \mathrm{g} / 5 \mu \mathrm{L}$ for SWATH acquisitions. Peptide digests were separated by using an Eksigent MicroLC 200 system equipped with Eksigent C18-reverse phase column $(100 * 0.3 \mathrm{~mm}, 3 \mu \mathrm{m}, 120 \AA$ A). Samples were analyzed on AB-SCIEX Triple TOF 5600 mass spectrometer. The LC separation methods and parameter settings for MS acquisitions have been followed as per the protocol of Korwar, et al. [83]. The mass spectrometry proteomics data have been deposited to the ProteomeXchange Consortium via the PRIDE [84] partner repository with the dataset identifier PXD011064.

Peptide spectral library and data base search - IDA mass spectrometric files were searched using ProteinPilot software, version 5.0.1.0.4874 (AB SCIEX) with the Paragon algorithm against in silico translated in-house C. grandis flower bud transcriptome at FDR (false discovery rate) $\leq 1 \%$. The ProteinPilot output file (.group) was used as a standard peptide spectral library. In order to identify proteins that might have gone undetected due to the limitation of Coccinia transcriptome database coverage, IDA mass spectrometric files were also searched against Cucumis sativus protein sequences available in Phytozome [85]. SWATH analysis was performed for six biological replicates and technical triplicates each from early-staged male, female, $\mathrm{Ag}-\mathrm{H}$ and GyM-H buds as well as middle-staged male, female, Ag-H and GyM-H buds. The spectral alignment and targeted data extraction of SWATH-MS data was performed using Peakview software, version 2.2 (AB SCIEX). The peptide data (.MRKVW) files were used for quantification of proteins using Markerview software, version 1.3 (AB SCIEX). Normalization was performed using $\beta$-galactosidase and actin-7 (TRINITY_DN116897) peak area followed by the total area sum. The peptides with a $P \leq 0.05$ were considered for quantification. PCA-DA analysis was carried out using Markerview in order to study the relationship between all the samples and replicates followed by $\mathrm{t}$-test to identify DEPs among each pairwise comparisons in which fold change was set as $\geq 1.5$, and significance of $P \leq 0.05$ was chosen as cut-off.

\section{Protein-protein interaction network analysis}

Accession ID of Arabidopsis thaliana homologs of the proteins identified by proteomic analysis were used to study the protein-protein interaction using Cytoscape 
3.6 [86]. The STRING database for Arabidopsis thaliana was used to import the annotation, interaction and further analysis was performed using STRING App 1.2.2 [87]. Gene enrichment analysis was performed and proteins grouped under reproductive process and floral development, were used for generating network representation.

\section{Transcript abundance analysis}

In order to estimate the transcript levels for selected differentially enriched proteins, qRT-PCR was carried out using the same tissue samples that were used for proteomics. Complementary DNA (cDNA) synthesis was performed with two micrograms of total RNA by SuperScript IV reverse transcriptase (Invitrogen) using an oligo(dT) primer. BIO-RAD CFX96 machine was used for carrying out the qRT-PCR with gene-specific forward and reverse primers (Additional file 10: Table S1). Takara SYBR Premix Ex Taq II (Takara Bio Inc.) was used for the reactions and PCR plates were incubated at $95^{\circ} \mathrm{C}$ for 3 min followed by 40 cycles of $95^{\circ} \mathrm{C}$ for $15 \mathrm{~s}, 58^{\circ} \mathrm{C}$ for $15 \mathrm{~s}$ and $72^{\circ} \mathrm{C}$ for $15 \mathrm{~s}$. Melting curve analysis was performed to ascertain PCR specificity. Data were analysed using the $2^{-\Delta \Delta C T}$ method and $C g A C T 2$ was chosen as a reference gene for normalization [88].

\section{Additional files}

Additional file 1: Data S1. Detailed report of protein identification from C. grandis flower buds using Paragon algorithm with ProteinPilot v5.0.1. (XLSX $12245 \mathrm{~kb}$ )

Additional file 2: Data S2. BLAST2GO annotation table for the $C$. grandis flower bud proteins detected in this study. (XLSX $640 \mathrm{~kb}$ )

Additional file 3: Figure S1. Enzyme code distribution analysis for the detected C. grandis flower bud proteins using BLAST2GO v5. (TIF $1214 \mathrm{~kb}$ )

Additional file 4: Figure S2. Heatmap depicting expression profiles of 2262 hierarchically clustered proteins from different stages of $\mathrm{C}$. grandis flower bud samples. AGE (Red), Early-staged Ag-H; AGM (Green), Middlestaged Ag-H; FE (Blue), Early-staged Female; FM (Turquoise), Middle-staged Female; GE (Pink), Early-staged GyM-H; GM (Yellow), Middle-staged GyM-H; ME (Grey), Early-staged Male; MM (Black), Middle-staged Male. (TIF 56 kb)

Additional file 5: Data S3. Normalized peak areas for each of the quantified proteins across all the samples and pairwise differential expression analysis results with respective fold-changes as well as $P$ values. DEPs with fold change $\geq 1.5$ and $P \leq 0.05$ are shown in highlighted cells for all pairwise comparisons. (XLSX $7759 \mathrm{~kb}$ )

Additional file 6: Figure S3. Venn diagram showing the overlap of differentially expressed proteins between all the pairwise comparisons at early (A) and middle stages (B) of flower development. (PDF $343 \mathrm{~kb}$ )

Additional file 7: Data S4. Overlap of differentially expressed proteins between all the pairwise comparisons at early stage of flower development. (XLSX $42 \mathrm{~kb}$ )

Additional file 8: Data S5. Overlap of differentially expressed proteins between all the pairwise comparisons at middle stage of flower development. (XLSX $38 \mathrm{~kb}$ )

Additional file 9: Data S6. Normalized peak areas for the proteins involved in male and female reproductive organ development, seed development and embryo development along with their respective Arabidopsis accession IDs. (XLSX $144 \mathrm{~kb})$
Additional file 10: Table S1. Primers used for $\mathrm{qRT}-\mathrm{PCR}$ in the current study. (PDF $39 \mathrm{~kb}$ )

\section{Abbreviations}

Ag-H flower buds: Hermaphrodite flowers from a plant treated with silver nitrate; GO: Gene Ontology; GyM: Gynomonoecious; GyM-H flower buds: Hermaphrodite flowers from a gynomonoecious plant;

IDA: Information Dependent Acquisition; LC-MS: Liquid ChromatographyMass Spectrometry; NGS: Next-Generation Sequencing; Nr: Non-redundant protein database; PCA-DA: Principal Component Analysis and Discriminant Analysis; qRT-PCR: Quantitative Real-Time PCR; SWATH-MS: Sequential Window Acquisition of All Theoretical Mass Spectra

\section{Acknowledgements}

Authors sincerely thank Dr. Mahesh Kulkarni and his PhD students, Biochemical Science Division, CSIR-NCL Pune for the critical discussion and suggestions throughout the study. We thank Mr. Nitish Lahigude for maintaining C. grandis plants in the green house as well as in the field. Dr. Narendra Kadoo's technical input with regards to protein isolation is also acknowledged. Technical inputs regarding LC-MS received from Dr. Shanthakumari, CSIR-NCL Pune are also thankfully acknowledged.

\section{Author's contributions}

RSD, JB, AKB, and SS planned and designed the research. RSD and TC performed experiments and analysed the data. RSD, TC, JB, BBD and AKB wrote the manuscript. AB, BBD and SS helped in critical discussion, interpretation of data and edited the manuscript. All authors have read and approved the final manuscript.

\section{Funding}

R.S.D. acknowledges research fellowship obtained from CSIR, HRDG, New Delhi. Financial support from DST, Govt. of India (Grant No-SR/WOS-A/LS1233/2014), and Director, IISER Pune are thankfully acknowledged. Funding body was not involved in the design of the study; collection, analysis, interpretation of data and in writing the manuscript.

\section{Availability of data and materials}

The mass spectrometry proteomics data have been deposited to the ProteomeXchange Consortium via the PRIDE partner repository with the dataset identifier PXD011064.

Ethics approval and consent to participate

Not Applicable

\section{Consent for publication}

Not Applicable

\section{Competing interests}

The authors declare that they have no competing interests.

\section{Author details}

'Biology Division, Indian Institute of Science Education and Research (IISER), Pune 411008, India. ${ }^{2}$ Biochemical Science Division National Chemical laboratory (CSIR-NCL), Pune 411008 , India. ${ }^{3}$ Academy of Scientific and Innovative Research (AcSIR), New Delhi, India. ${ }^{4}$ Department of Botany, Tripura University, Suryamaninagar, Tripura 799022, India. ${ }^{5}$ IPS2, INRA, CNRS, University Paris Sud, University of Evry, University of Paris Diderot, University of Paris Saclay, Batiment 630, 91405 Orsay, France. ${ }^{6}$ Department of Molecular Biology \& Bioinformatics, Tripura University, Suryamaninagar, Tripura 799022, India.

Received: 30 January 2019 Accepted: 11 July 2019

Published online: 23 July 2019

\section{References}

1. Yampolsky C, Yampolsky H. Distribution of sex forms in the phanerogamic flora. Bibliotheca Genetica. 1922;3:1-62.

2. Renner SS, Ricklefs RE. Dioecy and its correlates in the flowering plants. Am J Bot. 1995;82(5):596-606. 
3. Charlesworth D. Plant sex determination and sex chromosomes. Heredity. 2002;88:94.

4. Renner SS. The relative and absolute frequencies of angiosperm sexual systems: Dioecy, monoecy, gynodioecy, and an updated online database. Am J Bot. 2014;101(10):1588-96.

5. Ainsworth C. Boys and girls come out to play: the molecular biology of dioecious plants. Ann Bot. 2000;86(2):211-21.

6. Ainsworth C, Parker J, Buchanan-Wollaston V. Sex Determination in Plants. In: Pedersen RA, Schatten GP, editors. Current Topics in Developmental Biology. 38 Academic Press; 1997. p. 167-223. https://doi.org/10.1016/50070-2153(08)60247-1.

7. Guttman DS, Charlesworth D. An X-linked gene with a degenerate Y-linked homologue in a dioecious plant. Nature. 1998;393:263.

8. Ming R, Bendahmane A, Renner SS. Sex chromosomes in land plants. Annu Rev Plant Biol. 2011;62(1):485-514.

9. Dellaporta SL, Calderon-Urrea A. Sex determination in flowering plants. Plant Cell. 1993;5(10):1241.

10. Kouonon LC, Jacquemart A-L, Zoro Bi Al, Bertin P, Baudoin J-P, Dje Y. Reproductive biology of the andromonoecious Cucumis melo subsp. agrestis (Cucurbitaceae). Ann Bot. 2009;104(6):1129-39.

11. Kumar L, Deodikar G. Sex chromosomes of Coccinia indica Wight and Arn. Curr Sci. 1940;9(3):128-30.

12. Bhaduri PN, Bose PC. Cyto-genetical investigations in some common cucurbits, with special reference to fragmentation of chromosomes as a physical basis of speciation. J Genet. 1947;48(2):237.

13. Chakravorti A, editor Cytology of Coccinia indica W. \& A. with reference to the behaviour of its sex-chromosomes. Proceedings of the Indian Academy of Sciences-Section B; 1948: Springer.

14. Kumar L, Viseveshwaraiah S. Sex mechanism in Coccinia indica Wight and Arn. Nature. 1952;170(4321):330.

15. Bhowmick BK, Jha TB, Jha S. Chromosome analysis in the dioecious cucurbit Coccinia grandis (L.) Voigt. Chromosome Sci. 2012;15(1+ 2):9-15.

16. Sousa A, Fuchs J, Renner SS. Molecular cytogenetics (FISH, GISH) of Coccinia grandis: a ca. 3 myr-old species of Cucurbitaceae with the largest $\mathrm{Y} /$ autosome divergence in flowering plants. Cytogenet Genome Res. 2013; 139(2):107-18.

17. Bhuskute S, Makde K, Deshpande P. Staminal organization in Coccinia grandis (L.) Voigt. Ann Bot. 1986:415-8.

18. Ghadge AG, Karmakar K, Devani RS, Banerjee J, Mohanasundaram B, Sinha RK, et al. Flower development, pollen fertility and sex expression analyses of three sexual phenotypes of Coccinia grandis. BMC Plant Biol. 2014;14(1):325.

19. Di Stilio VS, Kramer EM, Baum DA. Floral MADS box genes and homeotic gender dimorphism in Thalictrum dioicum (Ranunculaceae) - a new model for the study of dioecy. Plant J. 2005;41(5):755-66.

20. Hardenack S, Ye D, Saedler H, Grant S. Comparison of MADS box gene expression in developing male and female flowers of the dioecious plant white campion. Plant Cell. 1994;6(12):1775.

21. Ainsworth C, Crossley S, Buchanan-Wollaston V, Thangavelu M, Parker J. Male and female flowers of the dioecious plant sorrel show different patterns of MADS box gene expression. Plant Cell. 1995;7(10):1583.

22. Beyer EM. A potent inhibitor of ethylene action in plants. Plant Physiol. 1976;58(3):268

23. McDaniel BK, Binder BM. Ethylene receptor 1 (ETR1) is sufficient and has the predominant role in mediating inhibition of ethylene responses by silver in Arabidopsis thaliana. J Biol Chem. 2012;287(31):26094-103.

24. Sarath G, Mohan Ram HY. Comparative effect of silver ion and gibberellic acid on the induction of male flowers on female Cannabis plants. Experientia. 1979:35(3):333-4.

25. Yin T, Quinn JA. Tests of a mechanistic model of one hormone regulating both sexes in Cucumis sativus (Cucurbitaceae). Am J Bot. 1995:1537-46.

26. Law TF, Lebel-Hardenack S, Grant SR. Silver enhances stamen development in female white campion (Silene latifolia [Caryophyllaceae]). Am J Bot. 2002; 89(6):1014-20.

27. Muyle A, Zemp N, Deschamps C, Mousset S, Widmer A, Marais GA. Rapid de novo evolution of $X$ chromosome dosage compensation in Silene latifolia, a plant with young sex chromosomes. PLoS Biol. 2012;10(4):e1001308.

28. Chibalina Margarita V, Filatov DA. Plant $Y$ chromosome degeneration is retarded by haploid purifying selection. Curr Biol. 2011;21(17):1475-9.

29. Bergero $R$, Charlesworth $D$. Preservation of the $Y$ transcriptome in a 10-millionyear-old plant sex chromosome system. Curr Biol. 2011;21(17):1470-4.

30. Akagi T, Henry IM, Tao R, Comai L. A Y-chromosome-encoded small RNA acts as a sex determinant in persimmons. Science. 2014;346(6209):646.
31. Harkess A, Mercati F, Shan H-Y, Sunseri F, Falavigna A, Leebens-Mack J. Sexbiased gene expression in dioecious garden asparagus (Asparagus officinalis). New Phytol. 2015;207(3):883-92.

32. Wu T, Qin Z, Zhou X, Feng Z, Du Y. Transcriptome profile analysis of floral sex determination in cucumber. J Plant Physiol. 2010;167(11):905-13.

33. Urasaki N, Tarora K, Shudo A, Ueno H, Tamaki M, Miyagi N, et al. Digital transcriptome analysis of putative sex-determination genes in papaya (Carica papaya). PLoS One. 2012;7(7):e40904.

34. Guo S, Zheng Y, Joung J-G, Liu S, Zhang Z, Crasta OR, et al. Transcriptome sequencing and comparative analysis of cucumber flowers with different sex types. BMC Genomics. 2010;11(1):384.

35. Devani RS, Sinha S, Banerjee J, Sinha RK, Bendahmane A, Banerjee AK. De novo transcriptome assembly from flower buds of dioecious, gynomonoecious and chemically masculinized female Coccinia grandis reveals genes associated with sex expression and modification. BMC Plant Biol. 2017;17(1):241.

36. Zhang B, Wang J, Wang X, Zhu J, Liu Q, Shi Z, et al. Proteogenomic characterization of human colon and rectal cancer. Nature. 2014;513:382.

37. Gygi SP, Rochon Y, Franza BR, Aebersold R. Correlation between protein and mRNA abundance in yeast. Mol Cell Biol. 1999;19(3):1720-30.

38. Yang L, Gong F, Xiong E, Wang W. Proteomics: a promising tool for research on sex-related differences in dioecious plants. Front Plant Sci. 2015;6:954.

39. Bracale M, Galli M, Falavigna A, Soave C. Sexual differentiation in Asparagus officinalis L. Sex Plant Reprod. 1990:3(1):23-30.

40. Golan-Goldhirsh A, Peri I, Birk Y, Smirnoff P. Inflorescence bud proteins of Pistacia vera. Trees. 1998;12(7):415-9.

41. Manzano S, Megías Z, Martínez C, García A, Aguado E, Chileh T, et al. Overexpression of a flower-specific aerolysin-like protein from the dioecious plant Rumex acetosa alters flower development and induces male sterility in transgenic tobacco. Plant J. 2017;89(1):58-72.

42. Boualem A, Fergany M, Fernandez R, Troadec C, Martin A, Morin H, et al. A conserved mutation in an ethylene biosynthesis enzyme leads to Andromonoecy in melons. Science. 2008;321(5890):836.

43. Boualem A, Lemhemdi A, Sari M-A, Pignoly S, Troadec C, Abou Choucha F, et al. The Andromonoecious sex determination gene predates the separation of Cucumis and Citrullus Genera. PLoS One. 2016;11(5):e0155444.

44. Boualem A, Troadec C, Camps C, Lemhemdi A, Morin H, Sari M-A, et al. A cucurbit androecy gene reveals how unisexual flowers develop and dioecy emerges. Science. 2015;350(6261):688.

45. Boualem A, Troadec C, Kovalski I, Sari M-A, Perl-Treves R, Bendahmane A. A conserved ethylene biosynthesis enzyme leads to Andromonoecy in two Cucumis species. PLoS One. 2009;4(7):e6144.

46. Switzenberg JA, Little HA, Hammar SA, Grumet R. Floral primordia-targeted ACS (1-aminocyclopropane-1-carboxylate synthase) expression in transgenic Cucumis melo implicates fine tuning of ethylene production mediating unisexual flower development. Planta. 2014;240(4):797-808.

47. Kim CY, Bove J, Assmann SM. Overexpression of wound-responsive RNAbinding proteins induces leaf senescence and hypersensitive-like cell death. New Phytol. 2008;180(1):57-70.

48. Chen H, Sun J, Li S, Cui Q, Zhang H, Xin F, et al. An ACC oxidase gene essential for cucumber carpel development. Mol Plant. 2016;9(9):1315-27.

49. Tao Q, Niu H, Wang Z, Zhang W, Wang H, Wang S, et al. Ethylene responsive factor ERF110 mediates ethylene-regulated transcription of a sex determination-related orthologous gene in two Cucumis species. J Exp Bot. 2018;69(12):2953-65.

50. O'Malley RC, Rodriguez Fl, Esch JJ, Binder BM, O'Donnell P, Klee HJ, et al. Ethylene-binding activity, gene expression levels, and receptor system output for ethylene receptor family members from Arabidopsis and tomato. Plant J. 2005:41(5):651-9.

51. Berg M, Rogers R, Muralla R, Meinke D. Requirement of aminoacyl-tRNA synthetases for gametogenesis and embryo development in Arabidopsis. Plant J. 2005;44(5):866-78.

52. Andème Ondzighi C, Christopher DA, Cho EJ, Chang S-C, Staehelin LA. Arabidopsis protein disulfide Isomerase- 5 inhibits cysteine proteases during trafficking to vacuoles before programmed cell death of the endothelium in developing seeds. Plant Cell. 2008;20(8):2205.

53. Spitzer C, Reyes FC, Buono R, Sliwinski MK, Haas TJ, Otegui MS. The ESCRTrelated CHMP1A and B proteins mediate multivesicular body sorting of auxin carriers in Arabidopsis and are required for plant development. Plant Cell. 2009;21(3):749.

54. Yang Y, Karlson DT. Overexpression of AtCSP4 affects late stages of embryo development in Arabidopsis. J Exp Bot. 2011;62(6):2079-91. 
55. Pagnussat GC, Yu H-J, Ngo QA, Rajani S, Mayalagu S, Johnson CS, et al. Genetic and molecular identification of genes required for female gametophyte development and function in Arabidopsis. Development. 2005;132(3):603.

56. Johnson MA, von Besser K, Zhou Q, Smith E, Aux G, Patton D, et al. Arabidopsis hapless mutations define essential Gametophytic functions. Genetics. 2004;168(2):971-82.

57. Saito S, Fujii N, Miyazawa Y, Yamasaki S, Matsuura S, Mizusawa H, et al. Correlation between development of female flower buds and expression of the CS-ACS2 gene in cucumber plants. J Exp Bot. 2007;58(11):2897-907.

58. Li Z, Huang S, Liu S, Pan J, Zhang Z, Tao Q, et al. Molecular isolation of the $M$ gene suggests that a conserved-residue conversion induces the formation of bisexual flowers in cucumber plants. Genetics. 2009;182(4): 1381.

59. Kotake T, Hojo S, Yamaguchi D, Aohara T, Konishi T, Tsumuraya Y. Properties and physiological functions of UDP-sugar Pyrophosphorylase in Arabidopsis. Biosci Biotechnol Biochem. 2007;71(3):761-71.

60. Smalle J, Kurepa J, Yang P, Emborg TJ, Babiychuk E, Kushnir S, et al. The pleiotropic role of the $26 \mathrm{~S}$ proteasome subunit RPN10 in Arabidopsis growth and development supports a substrate-specific function in abscisic acid signaling. Plant Cell. 2003;15(4):965-80.

61. Park J-I, Ishimizu T, Suwabe K, Sudo K, Masuko H, Hakozaki H, et al. UDPglucose Pyrophosphorylase is rate limiting in vegetative and reproductive phases in Arabidopsis thaliana. Plant Cell Physiol. 2010;51(6):981-96.

62. Toujani W, Muñoz-Bertomeu J, Flores-Tornero M, Rosa-Téllez S, Anoman AD, Alseekh S, et al. Functional characterization of the Plastidial 3-phosphoglycerate dehydrogenase family in Arabidopsis. Plant Physiol. 2013;163(3):1164-78.

63. Grienenberger E, Kim SS, Lallemand B, Geoffroy P, Heintz D, Souza CA, et al. Analysis of TETRAKETIDE a-PYRONE REDUCTASE function in Arabidopsis thaliana reveals a previously unknown, but conserved, biochemical pathway in Sporopollenin monomer biosynthesis. Plant Cell. 2010;22(12):4067-83.

64. Dobritsa AA, Geanconteri A, Shrestha J, Carlson A, Kooyers N, Coerper D, et al. A large-scale genetic screen in Arabidopsis to identify genes involved in pollen Exine production. Plant Physiol. 2011;157(2):947-70.

65. Van Damme D, Coutuer S, De Rycke R, Bouget F-Y, Inzé D, Geelen D. Somatic cytokinesis and pollen maturation in Arabidopsis depend on TPLATE, which has domains similar to coat proteins. Plant Cell. 2006;18(12): 3502-18.

66. Schilmiller AL, Stout J, Weng J-K, Humphreys J, Ruegger MO, Chapple C. Mutations in the cinnamate 4-hydroxylase gene impact metabolism, growth and development in Arabidopsis. Plant J. 2009:60(5):771-82.

67. Yang K, Wang H, Xue S, Qu X, Zou J, Le J. Requirement for A-type cyclindependent kinase and cyclins for the terminal division in the stomatal lineage of Arabidopsis. J Exp Bot. 2014;65(9):2449-61.

68. Zhu J, Wu X, Yuan S, Qian D, Nan Q, An L, et al. Annexin5 plays a vital role in Arabidopsis pollen development via Ca2+-dependent membrane trafficking. PLoS One. 2014;9(7):e102407.

69. Peng J, Ilarslan H, Wurtele ES, Bassham DC. AtRabD2b and AtRabD2c have overlapping functions in pollen development and pollen tube growth. BMC Plant Biol. 2011;11(1):25.

70. Dobritsa AA, Lei Z, Nishikawa S-I, Urbanczyk-Wochniak E, Huhman DV, Preuss D, et al. LAP5 and LAP6 encode anther-specific proteins with similarity to Chalcone synthase essential for pollen Exine development in Arabidopsis. Plant Physiol. 2010;153(3):937-55.

71. Kim SS, Grienenberger E, Lallemand B, Colpitts CC, Kim SY, Souza CA, et al. LAP6/POLYKETIDE SYNTHASE A and LAP5/POLYKETIDE SYNTHASE B encode Hydroxyalkyl a-Pyrone synthases required for pollen development and Sporopollenin biosynthesis in Arabidopsis thaliana. Plant Cell. 2010;22(12): 4045-66.

72. Berkowitz O, Jost R, Pollmann S, Masle J. Characterization of TCTP, the translationally controlled tumor protein, from Arabidopsis thaliana. Plant Cell. 2008;20(12):3430-47

73. Delmas F, Séveno M, Northey JGB, Hernould M, Lerouge $P, M c C o u r t ~ P$, et al. The synthesis of the rhamnogalacturonan II component 3-deoxy-D-manno2-octulosonic acid (Kdo) is required for pollen tube growth and elongation. J Exp Bot. 2008;59(10):2639-47.

74. Birke $H$, Heeg C, Wirtz M, Hell R. Successful fertilization requires the presence of at least one major 0 -acetylserine(thiol)lyase for cysteine synthesis in pollen of Arabidopsis. Plant Physiol. 2013;163(2):959-72.

75. Zhang D, Liu D, Lv X, Wang Y, Xun Z, Liu Z, et al. The cysteine protease CEP1, a key executor involved in Tapetal programmed cell death, regulates pollen development in Arabidopsis. Plant Cell. 2014;26(7):2939-61.
76. Dettmer J, Schubert D, Calvo-Weimar O, Stierhof Y-D, Schmidt R, Schumacher K. Essential role of the V-ATPase in male gametophyte development. Plant J. 2005;41(1):117-24

77. Forsthoefel NR, Vernon DM. Effect of sporophytic PIRL9 genotype on postmeiotic expression of the Arabidopsis pirl1; pirl9 mutant pollen phenotype. Planta. 2011;233(2):423-31.

78. Boavida LC, Shuai B, Yu H-J, Pagnussat GC, Sundaresan V, McCormick S. A collection of Ds insertional mutants associated with defects in male gametophyte development and function in Arabidopsis thaliana. Genetics. 2009;181(4):1369-85

79. Xu J, Yang C, Yuan Z, Zhang D, Gondwe MY, Ding Z, et al. The ABORTED MICROSPORES regulatory network is required for Postmeiotic male reproductive development in Arabidopsis thaliana. Plant Cell. 2010;22(1):91-107.

80. de Azevedo SC, Kim SS, Koch S, Kienow L, Schneider K, McKim SM, et al. A novel fatty acyl-CoA Synthetase is required for pollen development and Sporopollenin biosynthesis in Arabidopsis. Plant Cell. 2009;21(2):507-25.

81. Rhee SY, Osborne E, Poindexter PD, Somerville CR. Microspore separation in the quartet 3 mutants of Arabidopsis is impaired by a defect in a developmentally regulated Polygalacturonase required for pollen mother Cell Wall degradation. Plant Physiol. 2003;133(3):1170-80.

82. Isaacson T, Damasceno CMB, Saravanan RS, He Y, Catalá C, Saladié M, et al. Sample extraction techniques for enhanced proteomic analysis of plant tissues. Nat Protoc. 2006;1:769.

83. Korwar AM, Vannuruswamy G, Jagadeeshaprasad MG, Jayaramaiah RH, Bhat $\mathrm{S}$, Regin $\mathrm{BS}$, et al. Development of diagnostic fragment ion library for glycated peptides of human serum albumin: targeted quantification in Prediabetic, diabetic, and microalbuminuria plasma by parallel reaction monitoring, SWATH, and MSE. Mol Cell Proteomics. 2015;14(8):2150-9.

84. Vizcaíno JA, Csordas A, del-Toro N, Dianes JA, Griss J, Lavidas I, et al. 2016 update of the PRIDE database and its related tools. Nucleic Acids Res. 2016; 44(D1):D447-D56.

85. Goodstein DM, Shu S, Howson R, Neupane R, Hayes RD, Fazo J, et al. Phytozome: a comparative platform for green plant genomics. Nucleic Acids Res. 2011;40(D1):D1178-D86.

86. Shannon P, Markiel A, Ozier O, Baliga NS, Wang JT, Ramage D, et al. Cytoscape: a software environment for integrated models of biomolecular interaction networks. Genome Res. 2003:13(11):2498-504.

87. Szklarczyk D, Morris JH, Cook H, Kuhn M, Wyder S, Simonovic M, et al. The STRING database in 2017: quality-controlled protein-protein association networks, made broadly accessible. Nucleic Acids Res. 2017;45(D1):D362-D8.

88. Livak KJ, Schmittgen TD. Analysis of relative gene expression data using real-time quantitative PCR and the $2-\Delta \Delta C T$ method. Methods. 2001;25(4): 402-8.

\section{Publisher's Note}

Springer Nature remains neutral with regard to jurisdictional claims in published maps and institutional affiliations.

Ready to submit your research? Choose BMC and benefit from:

- fast, convenient online submission

- thorough peer review by experienced researchers in your field

- rapid publication on acceptance

- support for research data, including large and complex data types

- gold Open Access which fosters wider collaboration and increased citations

- maximum visibility for your research: over $100 \mathrm{M}$ website views per year

At BMC, research is always in progress.

Learn more biomedcentral.com/submission 